\title{
HABITUS PROFESSORAL NA SALA DE AULA VIRTUAL
}

\author{
Alexandre Marinho Pimenta \\ Carlos Lopes**
}

RESUMO: Entendendo que a indiferença na ação pedagógica contribui para a reprodução das desigualdades no sistema de ensino, o presente artigo busca captar, a partir de entrevistas semiestruturadas, traços do habitus de professores supervisores de disciplinas do curso de Licenciatura em Pedagogia na modalidade a distância na Universidade de Brasília - UnB no âmbito do Sistema Universidade Aberta do Brasil - UAB. As orientações metodológicas de Bourdieu (2007) foram um dos elementos orientadores na análise das entrevistas, considerando ainda o uso heurístico do conceito de habitus. Conclui-se que o habitus professoral envolve esforços voluntários em busca de uma ação pedagógica diferenciada. No entanto, ele é ambíguo e condescendente frente aos limites do modelo de EaD no âmbito da UAB. Ao fim, os dados analisados permitem fornecer elementos para reorientação político-pedagógica que vise a um novo modelo de EaD nacional.

Palavras-chave: Habitus Professoral. Educação a Distância. Diferenças. Virtual. Universidade Aberta do Brasil (UAB).

\footnotetext{
* Graduado em Pedagogia pela Faculdade de Educação/Universidade de Brasília-UnB; Mestrando do Programa de Pós-Graduação em Sociologia (UnB), na linha de pesquisa Educação, Ciência e Tecnologias. E-mail: alexmpsin@hotmail.com.

* Doutor em Sociologia (PUC-SP); Prof. do Departamento Teoria e Fundamentos - FE/UnB na área da Sociologia da Educação e no Programa de Pós-Graduação em Educação com pesquisas em Educação, Tecnologia e Comunicação. E-mail:carloslopes@unb.br
} 


\section{TEACHER'S HABITUS ON VIRTUAL CLASSROOMS}

ABSTRACT: By understanding indifference related to pedagogical action which contributes to inequalities reproduction in the education system, this paper seeks to capture, from semi-structured interviews, habitus traces of supervisor-teachers towards Pedagogy degree (distance education programs) at Brasilia University - UnB on the scope of Open System Brazilian University - OSBA. The methodological guidelines of Bourdieu (2007) were one of the guiding elements to interview analyses, mainly considering the heuristic use of habitus concept. It is concluded that its teacher's habitus involves volunteer efforts in search of a differentiated pedagogical action. However, it is ambiguous and complacent relative to limits of the distance education developed by OSBA. Furthermore, analysis data may provide elements to motivate political-pedagogical reorientation aimed to a new national model for distance education programs.

Keywords: Teacher's Habitus. Distance Education programs. Differences. Virtual. Open System Brazilian University (OSBA).

\section{INTRODUC̣ÃO}

A despeito da busca da universalização e da ampliação da qualidade do sistema de ensino, internacionalmente explícita nas políticas educacionais, o dualismo estrutural na educação persiste. A desigualdade social entre as classes ainda se mostra como grande responsável da desigualdade escolar nas sociedades modernas e contemporâneas. A posição objetiva no mundo social dos educandos em classes sociais opera uma divisão desigual de capital cultural ${ }^{1}$ necessário ao "sucesso escolar", que, por sua vez, legitima e reforça desigualmente posições sociais e de classe.

$\mathrm{Na}$ sociologia da educação, décadas de debate perpetuam a teoria da reprodução (BOURDIEU; PASSERON, 2009), que ganha, a cada formulação e retificação na atualidade, novos aspectos, sem com isso anular suas teses globais. Para Perrenoud (2001a, p. 114), a teoria da reprodução:

[...] postula, em resumo, que o fracasso escolar de parte dos alunos, a desigualdade das formações, não representa o fracasso do sistema de ensino, mas é sinal de seu sucesso com relação ao que dele esperam as classes privilegiadas: dar aos seus filhos uma formação escolar que corresponda ao capital cultural, social e econômico que lhes é transmitido pela família; favorecer uma certa mobilidade social, propícia ao desenvolvimento das ciências, das técnicas, da economia, em suma, dispor de uma população ativa cujas qualificações sejam proporcionais à divisão do trabalho. 
Assim, o sistema de ensino possui estreita relação com a estratificação social, a divisão do trabalho e com a as relações de dominação de classe, sendo o chamado fracasso escolar de um setor social um elemento "esperado" e necessário em certo nível, dada a sua real função: a reprodução das classes sociais e suas relações vigentes sob o regime de divisão social do trabalho.

Bourdieu (2010) postulava em sua teoria do sistema de ensino que, para que sejam favorecidos os mais favorecidos e desfavorecidos os mais desfavorecidos, o sistema educacional, incluindo a ação pedagógica deste, precisa ser indiferente frente às diferenças.

Essa incapacidade de lidar com as diferenças, com os capitais culturais diversos dos educandos e das classes, e pelo contrário, contribuir nas (re)produções das desigualdades educacionais e sociais através de uma seleção cultural arbitrária e de fundo sociopolítico, na prática, realiza-se pelo fato de o sistema de ensino ignorar, dissimuladamente, tal diversidade, e, por conseguinte, omitir-se frente a elas e, por isso, reprimi-las. "A igualdade formal que pauta a prática pedagógica serve como máscara e justificação para a indiferença no que diz respeito às desigualdades reais diante do ensino e da cultura transmitida, ou melhor dizendo, exigida" (BOURDIEU, 2010, p. 53).

No contexto atual, a Educação a Distância - EaD, ampliada e possibilitada pelas novas tecnologias da informação e comunicação (NTICs), como a informática e os serviços da internet, aponta-se como a oportunidade da virada do século para sanar as desigualdades educacionais e a reprodução destas. A democratização para populações e regiões antes excluídas do sistema de ensino ganha uma nova força e horizonte pela EaD.

Este artigo ${ }^{2}$ tem por objetivo analisar criticamente o habitus professoral na situação de docência num curso de graduação a distância oferecido pela Universidade de Brasília (UnB), no âmbito do sistema UAB, considerando a (in)diferença pedagógica presente e manifestada neste campo de ação.

\section{DESIGUALDADE E EDUCACุÃO}

A sociologia da educação atualmente tenta superar, refinar e atualizar o diagnóstico oferecido pelos teóricos da reprodução. Para Dubet (2001, p. 13), frente ao fatalismo político de uma reprodução acachapante, novas abordagens buscam um possível papel ativo e progressista da ação pedagógica frente as desigualdade. Em prefácio ao livro de Casassus (2007, p. vii), Touraine também desloca o centro 
gravitacional dos estudos sociológicos e educacionais para processos intraescolares, afirmando que "relações entre professores e estudantes são comprovadamente responsáveis pelo avanço da igualdade ou da desigualdade" no sistema educacional.

Para Perrenoud (2001a), o cenário do sistema de ensino se modificou, em alguns aspectos, desde que foram realizadas as denúncias dos teóricos da reprodução, pelo menos nos níveis básicos e obrigatórios, foco das análises do autor. Desde então, esforços sistemáticos podem ser identificados para combater o papel reprodutor e indiferenciado do sistema de ensino, tanto por parte do professor, quanto por parte das instituições e políticas. Casassus (2007, p. 48) também concorda ao afirmar que "o princípio de orientação curricular vigente não é mais o de formar uma população homogênea e sim de valorizar a diversidade": a democratização e o discurso focado na qualidade modificaram o paradigma educacional nos níveis políticos e pedagógicos.

No entanto, ainda é possível identificar diversas dificuldades para se barrar o motor da reprodução na prática. E mais: há indícios de que essa modificação se integra a novas formas de dominação de classe, cada vez mais sutis, e na reprodução renovada das desigualdades, hoje difusas (AYED, 2012, p. 784). Nessa linha, Dubet (2001, p. 9) afirma que "a igualdade [na educação] cresceu porque a educação não é mais um bem raro, beneficiando a todos, mas ela se tornou um bem mais hierarquizado quando as barreiras foram substituídas pelos níveis". Bourdieu (2010, p. 171) também já indicava a "multiplicação dos ramos de ensino sutilmente hierarquizados e das vias sem saída sabidamente dissimuladas que contribuem para perturbar a percepção das hierarquias". O sistema de ensino se encerraria, assim, numa posição cada vez mais paradoxal, também presente nas sociedades pós-modernas: renovação constante para conservação do essencial. É necessário salientar que, para Bourdieu (2002), o sistema de ensino é um dos mecanismos que contribui para perpetuar as estruturas sociais ${ }^{3}$. Bourdieu (2002) enfatiza que o sistema de ensino apenas contribui, a seu modo, para a reprodução social, e não a realiza por completo.

\section{HABITUS PROFESSORAL}

Dentre as dificuldades para barrar a reprodução, estão a falta de formação deliberada de um habitus profissional racional e consciente (PERRENOUD, 2001b) e a de condições para um trabalho docente eficiente e diferenciado (PERRENOUD, 2001a). Isso tudo força o 
professor a atuar sobre as diferenças na improvisação e no "fogo da ação", sendo, assim, forçado a ser indiferente às diferenças.

Partimos da compreensão de Silva (2005, p. 161), ao dizer que o habitus professoral faz parte do conjunto de elementos que estruturam a epistemologia da prática, sendo que na estética dos atos do professor reside o modo de ser e de agir docente.

O termo habitus não foi inventado por Bourdieu, seu mais famoso conceituador. $O$ autor se remete a uma noção filosófica antiga utilizada por outros sociólogos anteriores a ele, como Durkheim, para se referir a um estado geral profundamente arraigado de indivíduos (SET'TON, 2002, p. 61). Wacquant (2007, p. 66) sintetiza a noção de habitus em Bourdieu como

modo como a sociedade se torna depositada nas pessoas sob a forma de disposições duráveis, ou capacidades treinadas e propensões estruturadas para pensar, sentir e agir de modos determinados que opera como uma mola que necessita de um gatilho externo e não pode ser considerado isoladamente dos mundos sociais particulares, ou "campos", no interior dos quais evolui (WACQUANT, 2007, p. 69).

Para Bourdieu (2008, p. 22), "'o habitus são princípios geradores de práticas distintas e distintivas [...] mas também são esquemas classificatórios, princípios de classificação, princípios de visão e de divisão". O habitus media a posição social de um indivíduo/grupo e a ação deste, local de disposições e potencialidades, construídas e propulsoras de práticas e estruturas sociais.

Esse habitus se configura como uma durabilidade flexível, mais ou menos rígida, de complexas estruturas captáveis em práticas e situações específicas dentro de um campo. O habitus professoral, no caso, é construído-acionado no campo educacional, campo de disputa de capitais e de violência simbólica - reprodução/ruptura. Este trabalho toma o conceito de habitus e, especificamente, o de habitus professoral em seu valor heurístico, realizando a discussão em torno da situação da docência e ação pedagógica no campo da EAD. Como bem afirma Boltanski (2005, p. 162), uma sociologia centrada no conceito de habitus não pode deixar de fazer uma articulação em torno da noção de situação. Assim, a posição dos docentes entrevistados se insere em uma nova situação: os modos de agir em disciplinas de um curso de graduação a distância de instituição pública de ensino superior que participa e se insere num sistema denominado UAB, instituído no Brasil no ano de 2005. Portanto, o habitus professoral tomado enquanto perspectiva heurística de análise é atualizado em suas disposições na docência em EaD. Vale ressaltar que o estudo do habitus professoral permite desvelar os mecanismos 
de reprodução das desigualdades na educação, mas também dá pistas para intervir nos determinantes do sistema de ensino.

\section{EAD POR MEIO VIRTUAL: A DESIGUALDADE PARA ALÉM DO REAL}

A EaD é uma modalidade de educação que se caracteriza pelo fato de o professor e os alunos estarem em lugares e tempos diversos, ocorrendo a mediação pedagógica por meio das tecnologias da informação e comunicação (BRASIL, 2005). Nessa interação pedagógica de modelo flexibilizado, a relação entre o educador e o educando se dá pela mediação de tecnologias diversas.

$\mathrm{O}$ advento e a massificação da informática, junto aos serviços e espaços multimídias da internet, possibilitou, nas últimas décadas, o avanço da EaD baseada no ambiente virtual.

No Brasil, a EaD, conceito já presente na LDB de 1996 e que recebeu recentemente uma regulamentação mais precisa com o Decreto $n^{\circ} 5.622$ de 2005, é cada vez mais considerada nas políticas públicas educacionais. Essa modalidade de ensino tem crescido vertiginosamente, tanto se levar em consideração o número de matrículas, quanto o número de instituições, sobretudo no setor privado. Segundo o resumo técnico do Censo da Educação Superior de 2011 (MEC/INEP, 2013), já são mais mil cursos de graduação operando no país na modalidade a distância, representando quase $15 \%$ dos estudantes desse nível de todo o Brasil, sendo a licenciatura o grau acadêmico de maior predominância na EaD.

Presencia-se, na literatura especializada, uma forte polêmica em torno das políticas expansionistas da EaD como mecanismo de democratização do ensino, assim como da modalidade a distância em si. Diversas críticas e ponderações têm adiado um consenso maior entre a sociedade civil e política em relação à EaD e às atuais políticas que versam sobre esta.

Em relação a temática do artigo, Wolton (2007) apresenta uma importante contribuição. Criticando visões apologéticas das NTICs, o autor afirma que as novas características provindas das peculiaridades comunicacionais e sociabilidades do formato virtual não anulam o mundo social, nem, por conseguinte, suas hierarquias e desigualdades estruturais e determinantes. $O$ virtual, assim, não seria um mundo à parte, ou um novo mundo como quer parecer mostrar o manto ideológico, mas um campo dentro do mundo social e da história.

Assim há uma troca, um entrelaçamento, entre virtual e real, onde o mundo social é a sua base. O próprio acesso à rede, por 
exemplo, depende de condições materiais e subjetivas, impondo assim novas barreiras - como a exclusão digital. Assim como a própria "rede" não se assenta sobre a neutralidade sociopolítica do período histórico e geográfico em questão, a informação no mundo virtual depende tanto em sua construção e disseminação, quanto em sua apreensão de esquemas culturais arbitrários, de escolhas arbitrárias, longes da neutralidade de uma rede pretensamente aberta a todos (WOLTON, 2007, p. 97).

\section{O SISTEMA UNIVERSIDADE ABERTA DO BRASIL - UAB}

A EaD no Brasil ganha um novo marco com a criação da UAB. A UAB se insere dentro do marco da reforma da educação superior brasileira que vem ocorrendo nos últimos anos.

Segundo textos oficiais publicados na página eletrônica da $\mathrm{UAB}^{4}$, a UAB inicia suas atividades em 2005, com sua criação pelo MEC em parceria com a ANDIFES e Empresas Estatais, no âmbito do Fórum das Estatais pela Educação com foco nas Políticas e a Gestão da Educação Superior. Sendo um marco da EaD brasileira que segue tendências internacionais, a UAB consolida-se legalmente com o Decreto n. ${ }^{\circ} 5.800$ de 2006 . Seus objetivos são a democratização da educação superior para as camadas da população e regiões antes excluídas desse nível educacional, a formação e capacitação de professores da educação básica no país com a utilização de tecnologias e o aprimoramento da educação a distância no Brasil. A UAB é uma política pública que articula a então Secretaria de Educação a Distância, ainda existente no governo Lula ${ }^{5}$, e a Diretoria de Educação a Distância - DED/Coordenação de Aperfeiçoamento de Pessoal de Nível Superior - CAPES com vistas à expansão da educação superior, condensadas no PDE do governo Lula (2007).

A UAB é um sistema em que vários agentes participam e cooperam: CAPES - que é o órgão financiador, coordenador e fiscalizador do sistema; Instituição Pública de Educação Superior (IPES) - ofertante dos cursos a distância, organizadora em nível pedagógico; e o Governo do Distrito Federal, Estados e Municípios - proponentes de polos de apoio presencial à educação a distância e sua manutenção. No modelo UAB, a EaD ocorre em sua forma híbrida com a realização de encontros presenciais, porém com o predomínio da interação virtual. Os profissionais possuem um vínculo de bolsa, de caráter temporário, não acumulável, concedido pela CAPES/MEC e pagas pelo Fundo Nacional de Desenvolvimento da Educação - FNDE/MEC. 
A UnB, desde 2005, utiliza a plataforma Moodle ${ }^{6}$ como seu ambiente virtual de aprendizagem, e isso inclui o sistema UAB. Hoje a UAB-UnB atua em diversos estados com nove cursos de graduação, em sua maioria, licenciatura. No último vestibular (2013), o sistema ofereceu 1410 vagas em dezenas de polos municipais. E sua tendência é ampliar-se, focando também na formação (sobretudo docente) no nível de pós-graduação, principalmente lato sensu e mestrados profissionais, para atingir metas estatais/governamentais cada vez mais elevadas, presentes, por exemplo, no novo Plano Nacional de Educação - PNE, ainda em tramitação no parlamento brasileiro.

Está presente no texto Objetivos do Programa $U A B$ na UnB, na página eletrônica da UAB-UnB, o princípio educativo "Diversidade sociocultural como recurso para uma pedagogia diferenciada". Mas tal princípio, que, como visto, simboliza uma mudança de paradigma, efetiva-se na prática, mediante um habitus professoral e ação pedagógica correspondentes?

\section{METODOLOGIA}

A pesquisa de caráter exploratório possui uma abordagem qualitativa, a partir de entrevistas semiestruturadas. Foram realizadas entrevistas semiestruturadas com três docentes (professores supervisores) de disciplinas obrigatórias do curso de Licenciatura em Pedagogia da Universidade de Brasília (UnB) no âmbito do sistema UAB. A técnica de entrevista em profundidade cumpre o objetivo de caráter exploratório, apoiando-se em outras referências bibliográficas e no domínio teórico sobre o tema e o campo em questão, tornando possível realizar processos indutivos. O critério de escolha dos entrevistados foi a sua disponibilidade em participar das entrevistas. A delimitação de um curso de graduação visou dar uma maior consistência à análise.

Já a escolha pelos professores supervisores ${ }^{7}$ vinculados à Universidade de Brasília, e não a dos tutores que atuam a distância e presencialmente nos polos, busa verificar, com maior ênfase, as especificidades das relações pedagógicas frente às diferenças num ambiente de relacionamento quase por completo virtual, marcado fortemente pelo uso da comunicação escrita e da distância geográfica e, em menor escala, o uso da oralidade e a interação presencial, eventualmente possíveis em encontros presenciais e webconferências. Assim, essa escolha busca esclarecer melhor como ocorre a indiferenciação pedagógica numa função de 
supervisão, muito comum à divisão do trabalho pedagógico na modalidade EaD/UAB-UnB.

A princípio, as entrevistas continham 07 (sete) questões, divididas em três grandes eixos que buscavam identificar o habitus professoral e sua relação com o campo escolar/acadêmico e espaço social mais amplo, e também com sua ação pedagógica frente a diferenças dos estudantes no ambiente virtual e suas estratégias e concepções político-educacionais na EaD, além de suas modificações no habitus profissional inicial.

Tomou-se como referencial para análise das entrevistas as reflexões metodológicas realizadas por Bourdieu (2007). Culminando num método singular nomeado pelo autor de reflexividade reflexa, essas reflexões e apontamentos coadunam com o esforço teórico e de pesquisa do autor durante sua carreira na busca de escapar dos determinismos (tanto o subjetivismo quanto o objetivismo) que imperam na análise científica do mundo social, assim como do positivismo no campo epistemológico.

Para Bourdieu (2007), as bases epistemológicas estanques refletem na metodologia, fazendo surgir uma dicotomia estrita e forçada entre a pesquisa de tipo qualitativo e a de tipo quantitativo, cada qual reforçando sua base determinista. Além disso, o positivismo,

com seu ingênuo sonho de neutralidade epistemológica, esquece que a própria entrevista ou o ato de pesquisa é uma relação social, dentro de um campo (podendo por isso exercer-se como violência simbólica, dadas as disparidades entre pesquisador-pesquisado), e, por ter esse caráter, carrega seus efeitos sobre os resultados obtidos (BOURDIEU, 2007, p. 694)

que, antes de ser negados, devem ser controlados pelo pesquisador, destacado aqui a um papel fundamental e ativo. Assim,

[...] estas distorções devem ser reconhecidas e dominadas; e isso na própria realização de uma prática que pode ser refletida e metódica, sem ser a aplicação de um método ou a colocação em prática de uma reflexão teórica (BOURDIEU, 2007, p. 649).

Uma metodologia guiada para entrevistas deve tomar cuidado para não cair nas armadilhas já criticadas por Bourdieu no campo teórico. A entrevista não deve se render por completo ao dado, ao empírico, mas basear-se fortemente no conhecimento do pesquisador sobre o campo social pesquisado, já que este tem o dever de perceber e fazer aparecer os imperativos da estrutura social (objetiva) nas expressões subjetivas, singulares e conjunturais da entrevista. A reflexividade reflexa só se faz na prática, e construída na hora da 
prática, numa relação de "escuta ativa e metódica" (BOURDIEU, 2007, p. 695), e não de pura passividade do pesquisador, que, apesar de se esforçar numa comunicação não-violenta e de certa proximidade, deve saber compartilhar da comunicação do entrevistado e “à maneira de um parteiro" (BOURDIEU, 2007, p. 708); saber fazer brotar frutos e efeitos sociais enterrados de maneira mais ou menos inconsciente nas posições e disposições do entrevistado.

De forma geral, a noção de reflexividade reflexa orientou a atenção na realização e análise das entrevistas. Vale destacar que, neste artigo, assume-se a perspectiva de Sousa (2012), que, atento à perspectiva da reflexividade reflexa, assume que o conceito de habitus não deve ser reificado como coisa dada e que determinada ação possa ser imediatamente compreendida pelo simples a priori conceitual. Assim, entende o autor que o conceito orienta a leitura e a intervenção na realidade, mas o confronto com a realidade pode fazer emergir novos conceitos.

\section{ANÁLISE DAS ENTREVISTAS}

Primeiramente, um breve mapeamento da posição no espaço social dos agentes entrevistados e sua relação com o campo em questão. Todos os docentes tiveram a sua formação acadêmica no sistema público de ensino superior (da graduação ao doutorado). Um docente entrevistado graduou-se em História e fez o doutorado também em História. Outro entrevistado graduou-se em Psicologia e fez o doutorado em Sociologia. Por último, houve a entrevista com um docente formado em Pedagogia e com doutorado em Educação.

Os docentes entrevistados, formados nas áreas de humanas ou sociais, possuíam experiência mais ou menos largas, sejam pessoais ou profissionais em EaD (coordenação, planejamento e implementação de cursos, estudos e formação acadêmica na área). Da mesma forma, todos possuíam vários anos de experiência docente e algum tipo de militância ou preocupações políticas em pelo menos alguma fase da vida, que incluem a busca progressista por democratização da educação - em geral pública. Assim, pode-se afirmar que o habitus professoral dos entrevistados, antes mesmo no curso de formação docente para atuar na UAB, estava "preparado" para lidar com as tecnologias e as lógicas da EaD, assim como era sensível às diferenças e desigualdades culturais, sob a égide ideológica das classes médias de intuitos democráticos. 
Do ponto de vista ideológico, um entrevistado expressou a passagem de uma formação orientada pela dialética marxista para uma abordagem fenomenológica-hermenêutica, adotando atualmente uma posição menos militante no campo das disputas políticas no meio acadêmico. Certa postura contemplativa e de relativismo cultural diante dos fatos refletem, na sua autoanálise, a mudança de época - referindo-se à ditadura militar em comparação ao momento atual do Brasil - a sua faixa etária, as influências das instituições onde estudou na formação das suas ideias. Todavia, este docente entrevistado não abandonou, no seu modo de ser e agir, a perspectiva da luta e da transformação social. Dois outros entrevistados têm formação marxista, tendo propensões estruturadas a partir dessa perspectiva crítica de análise da sociedade. Ambos têm posição militante no campo dos temas e questões educacionais. Quando um entrevistado afirma Pra pensar essa realidade que tava lá, desse mundo que não era tão bonitinho (ENTREVISTADO 2), orienta sua ação por desvelar ilusões, tentando ultrapassar barreiras e simulacros propagados no nível da política para alcançar determinados fins. Já outro entrevistado diz que o principal problema da sociedade [brasileira] é a desigualdade social (ENTREVISTADO 3), situando ainda a sua visão e trajetória em processos de desvelamentos das "dinâmicas de alienação" no meio social, identificando-se com o entrevistado anterior em relação à causa sociopolítica nacional.

A partir daqui, será demonstrado como se dá a manifestação e reconstrução desse habitus, produzido socialmente mediante a posição desses sujeitos, se expressando no mundo prático, seja na esfera perceptiva/intuitiva ou propriamente no âmbito da ação, no caso, pedagógica, ressaltando a não dicotomia entre as duas esferas.

\section{Perfil discente}

Os docentes tiveram dificuldades em mapear o perfil socioeconômico e sociocultural de seus alunos. Sua função supervisora limitava um contato direto e frequente com os alunos. Suas percepções se embasavam por intuições, observações e análises dos fóruns de discussão (plataforma Moodle), comparações com o curso presencial, ou até mesmo, como foi o caso de um docente, por pesquisa independente sobre o perfil dos alunos.

O sistema de tutoria possui um papel central para a ação pedagógica em relação aos estudantes. Os tutores são os que possuem mais contato com os alunos, um conhecimento maior da realidade dos polos, e os professores supervisores se servem 
da interlocução constante com os tutores para mapeamento dos educandos e reordenamento da ação pedagógica no ambiente virtual e planejamento dos encontros presenciais.

Porém, de maneira geral, os docentes concordam que o público da $\mathrm{UAB}$ (curso a distância da $\mathrm{FE} / \mathrm{UnB}-\mathrm{UAB}$ ) é diferente do curso presencial correspondente, e, apesar de heterogêneo, com alunos que o fazem por necessidade e falta de alternativa em relação ao acesso ao ensino superior público em município polo ou "por conveniência", possui uma maior quantidade de pessoas com mais idade e oriunda das camadas populares. O entrevistado 1 chegou a afirmar que é comum e esperado ocorrer esse fenômeno, já que a flexibilização que a EaD possibilita atrai localidades e setores da sociedades que não possuem, na maioria das vezes, as mesmas oportunidades e condições de vida do aluno do curso presencial. A pesquisa de Lopes, Lisniowski e Jesus (2012), ao tratar das causas de evasão em alguns polos da $\mathrm{UAB} / \mathrm{UnB}$, apontou que a idade média dos alunos a distância do curso de Pedagogia é de 33 anos, e quase $40 \%$ já são professores em exercício. Já na amostra de 37 alunos evadidos, percebeu-se que a maioria era casada $(51,4 \%)$ e $43,2 \%$ estavam na faixa salarial de 0 a 900 reais (até dois salários mínimos). Além disso, 94,6\% dos alunos trabalhavam quando frequentavam o curso, incluindo 6 alunos que trabalhavam além de 40 horas semanais.

As defasagens mais comuns entre os alunos, detectadas pelos docentes, estão relacionadas ao capital cultural, que inclui conhecimento, convivência e acesso a meios culturais, escolares ou não, e artísticos valorizados, assim como o domínio da informática e ao capital linguístico. Como dito, mesmo o sistema da UAB sendo híbrido, com possíveis encontros presenciais, o uso da escrita predomina: é a principal forma de comunicação em ambiente virtual. Logo, em grande parte, é por meio de textos que as diferenças e desigualdades se explicitam para o professor supervisor.

Os entrevistados supervisionam disciplinas entre o meio e final de curso. Logo, percebe-se a permanência das defasagens, indo para além dos primeiros semestres e não superadas de maneira categórica ao longo da formação. Novamente, na pesquisa de Lopes, Lisniowski e Jesus (2012), a amostra analisada dos evadidos indicou que $40,5 \%$ dos alunos estudavam até duashoras por semana (muito aquém da orientação de 20 horas semanais existente no curso), e 13, $5 \%$ escolheu a modalidade a distância porque "parecia mais fácil".

Importante ressaltar, em relação às defasagens, que as entrevistas apresentaram notórias diferenças entre os polos: alguns, de maior 
proximidade à Brasília (DF) e de ambiente mais próximo do urbano, tinham mais facilidade, maior acesso aos bens culturais; já o polo de Carinhanha (BA), por exemplo, apesar do forte interesse e vontade de adaptação e legitimação em relação ao sistema UAB, apresentava maiores dificuldades pedagógicas por se situar em localidade mais rural. Em relação aos desníveis, um docente até indicou que deveria haver um nivelamento, um reforço em questões de defasagem escolar, com ênfase na língua portuguesa e redação, já que o próprio público é mais "velho", distante há muito tempo da escola, numa lógica de vida que não usa tanto a escrita e a argumentação científica. Outro indicou grupos de apoio, em vez de um nivelamento, entendido como pré-requisito individual para a continuidade do curso.

Para o entrevistado 2, discutir nivelamento é um foco errôneo. $\mathrm{Na}$ realidade, o que deveria ser discutido era o modelo de EaD. A princípio, essa modalidade deveria propor um modelo de flexibilização diferenciada, geográfica e culturalmente, que levasse em conta a realidade dos alunos e das regiões, no objetivo de oferecer qualidade, independendo do modo ou tecnologia:

[...] a questão da EaD não é que deveria ter pré-requisito, o curso deveria ser pensado de acordo com a turma. Por exemplo, se eu tô dizendo que a EaD é pra chegar pra todo mundo, então não posso achar que a EaD não pode ser somente via internet/computador, porque tem lugares que não tem. A questão não é prérequisito, deveria ter um conhecimento de que aluno é esse e oferecer a $\mathrm{EaD}$ com diferentes meios, um meio que a gente utiliza é a internet. (ENTREVISTADO 2)

Segundo Wolton (2007, p. 135), "se não se tem competência para assimilar o aprendizado, os sistemas de informação e de conhecimento erguerão outros tantos muros intransponíveis". A autonomia frente às NITCs exigem etapas, ou seja, não é inata, pois estas se movem num mundo cultural, espaço-tempo intersubjetivo. Veja-se a importância que cumpre o capital linguístico para a comunicação nas plataformas virtuais.

\section{Diferenciação, possibilidades e limites}

Notou-se que todos os docentes se utilizam claramente de mecanismos de flexibilização e adaptação do programa da disciplina, tanto na hora da (re)formulação de disciplinas, quanto no decorrer do semestre por meio do fórum virtual e da comunicação entre discentes e docentes, como o entrevistado 1 disse, no andar da carruagem, a gente vai corrigindo uma série de coisas. 
A organização da disciplina em ambiente virtual, por temáticas e não por semanas ${ }^{8}$, comum a dois dos entrevistados, é uma típica flexibilização temporal, que possibilita a ampliação dos prazos de entrega das tarefas por solicitação dos alunos. Já outro entrevistado disse que costuma deixar os fóruns "abertos" por mais tempo que o previsto, também mediante explicação ou pedido dos estudantes.

Essa flexibilização temporal, pode ter tanto um caráter mais individual - casos de pessoas específicas que tiveram problemas ou dificuldades para envio - ou um caráter mais grupal, casos de ausência de acesso à internet no polo, por exemplo.

Afirmam os entrevistados que as condições objetivas da UAB e de alguns alunos são muito variadas e diversas vezes ruins (recorrentes falhas na plataforma, falta de ou pouco acesso à internet de alta velocidade ou a materiais essenciais para a realização das tarefas, e de transporte até o polo), e uma rigidez semelhante ao curso presencial seria não levar em conta essas condições e prejudicar os alunos. Interessante notar que o entrevistado 3 criticou a flexibilização por achar que gera sobrecarga para os tutores, já que todos os problemas e dificuldades enfrentados pelos alunos acaba caindo no tutor [cargo]. Mecanismos compensatórios de recuperação, como mudança ou adição de avaliações e atividades, não ficaram tão explícitos nas entrevistas. Todavia, há indícios de que, juntamente com a flexibilização temporal, estes estejam presentes no decorrer da disciplina. Como se percebe na fala do entrevistado 2: o aluno pra chegar no final [do cronograma] em processos de recuperação é porque não tinha feito [as atividades]. Por exemplo, ele não tinha conseguido fazer atividade final, então a gente encaminhava mais uma vezpra ele fazer com o tutor presencial.

O entrevistado 1 comenta que a individualização do atendimento pedagógico, que inclui percepção da dificuldade para posterior ação, na modalidade a distância, existe, apesar de ser mais demorada se comparada ao presencial:

$\mathrm{E}$ as reuniões periódicas com os tutores [presenciais] e os tutores a distância, vão fazendo com que a gente vá afinando e em alguns casos a gente vai até individualizando o atendimento. Uma coisa é você falar em turma (presencial). Eu, por exemplo, eu posso aqui parar contigo e tirar uma dúvida sua, ficar 30, 40 minutos aqui, a gente conversando sobre uma dúvida. Isso como aconteceria a distância? Quando o tutor presencial identifica a questão, me passa e eu e ele vamos ter contato direto com esse aluno, esse atendimento diferenciado. Não é aquela coisa de escritório de contabilidade que manda uma carta igual para 150 pessoas.

Em relação à expectativa da docência na UAB e à prática docente no sistema, segundo um docente, houve uma ruptura. 
O povo da UAB dizia: “o que vocês quiserem, que a gente garante!”. Na prática, a gente descobriu que não era assim, que não tinha nada disso. Então a segunda [disciplina que ofertei] foi pensada mais com o pé no chão, pra pensar essa realidade que tava lá, desse mundo que não era tão bonitinho quanto o pessoal da UAB dava pra gente no curso de formação. Então a gente foi desvelando essas ilusões. (ENTREVISTADO 2).

Sendo o docente atravessado tanto pela ideologia/apologia tecnológica de hoje, assim como pelo discurso otimista da política de EaD, este, na situação prática contraditória é pressionado a subordinar-se a tal estrutura ou romper com ela, mas o que se desvela no habitus professoral é a tendência à ação pedagógica realista, correspondente no campo político à resistência realista ${ }^{9}$, como será abordado mais a frente.

Segundo Wolton (2007, p. 106), as NTICs adicionam uma nova burocracia à burocracia "humana", como nos casos de inflexibilização e novas barreiras na EaD, diminuindo o tempo de preparo e atenção propriamente pedagógica. Desmente-se assim a ilusão de um mundo virtual totalmente transparente. Além disso, as facilidades provindas da tecnologia muitas vezes se revertem em ampliação e intensificação de esforços e processos não existentes na docência presencial: a flexibilização pode, até mesmo, fragmentar-se e ocupar o tempo antes de lazer e reforçar a carga de trabalho.

Outro exemplo de inflexibilidade é a proposta do entrevistado 3 sobre um maior rigor/punição em relação à presença dos professores tutores nas reuniões pedagógicas. Isso demonstra um habitus para a sala de aula virtual, ao criar normatividades e regulações mais rígidas (união coesa da equipe pedagógica), que contraria o imaginário totalmente flexível sobre a EaD. Nota-se também que essa indiferenciação e inflexibilidade dentro da equipe pedagógica busca trazer, voluntariamente, ao sistema, melhores condições pedagógicas, encarnando-se numa paradoxal postura de disputa do campo. Uma pretensão democrática, mas que reforça relações de distinção, indicando formatos de poder simbólico e legitimação entre o professor supervisor e o professor tutor, dentro da forte divisão do trabalho pedagógico da EaD. Assim, nota-se certo mal-estar na divisão do trabalho pedagógico fundado numa lógica do sistema de bolsas que faz parte e se amplia nos "nós" do sistema UAB, condicionando as práticas educativas e pedagógicas.

Muitos outros esforços voluntários, que geram até sobrecarga docente e buscam superar as limitações do sistema, como doação de livros, digitalização de textos, entrega de vídeos em mídias nos polos, 
são realizados pelos professores e tutores para reverter as condições objetivas que prejudicam o processo de ensino-aprendizagem.

Em relação às críticas ao formato da $\mathrm{UAB}$, todos os docentes tocam na questão do sistema de tutoria, nas dificuldades encontradas na plataforma virtual (Moodle) ou nos polos, e de maneira mais ou menos direta à política educacional que coordena a EaD/UAB. Essa política forja um sistema UAB como uma espécie de sistema de ensino paralelo à instituição de ensino superior, um sistema de aspecto secundário. Essa secundarização, ou, como disse um dos entrevistados, essa "falta de sinergia", pode ser vista nos pontos criticados, mas também pelo não reconhecimento da carga horária de trabalho na graduação a distância na instituição, representando um baixo nível de institucionalização da $\mathrm{EaD}$, no sentido orgânico, e não meramente superficial. $O$ entrevistado 3 chegou a sugerir a retirada da bolsa que ganha como professor supervisor, caso houvesse reconhecimento do trabalho que faz na UAB como um trabalho próprio da UnB: não me dê a bolsa, então! E considere o meu trabalho na $U A B$ como um segundo trabalho pra universidade. Todos os entrevistados também comentaram sobre uma continuidade e reciprocidade entre a preparação de aulas para o presencial e o virtual, que reforçaria o sentido de união dos trabalhos e cargas horárias.

Presenciamos o nascimento de uma nova dualidade intrainstitucional, numa proposta que veio para banir qualquer dualismo educacional. Frigotto (2011, p. 247), analisando as reformas educacionais de modelo desenvolvimentista do governo Lula, diz que:

especialmente pelo crescimento do enclave da educação à distância, em alguns casos com a defesa de sua crescente expansão em substituição ao educação superior presencial, produz-se mais uma forma de dualidade. O fetiche da tecnologia opera aqui como argumento ideológico.

O professor supervisor age dependendo muito da comunicação com os tutores e do comprometimento destes, como dito. E, atualmente, o contrato dentro do sistema bolsista de tutoria é muito frágil: curto período de atuação, grande rotatividade de profissionais e uma bolsa de valor muito baixo. Todos os entrevistados criticaram essa situação:

Eu acho que [é um problema] a precarização da situação [dos professores tutores], eu coloco isso como uma precarização, por que é muito flexível, a situação do tutor é muito imprevisível. [...] Eu acho que deveria ter um status diferente o tutor, me parece que ele é uma espécie de solução temporária sempre. Que é um temporário que acaba se perenizando. (ENTREVISTADO 1) 
O entrevistado 3 afirma que o tutor permanece em sua função muito mais por um status simbólico do que pelo ganho salarial, ou até mesmo vê a atividade como um "bico". O entrevistado 2 afirma que a proposta da UAB insiste, de maneira errônea, em chamar os profissionais que acompanham os processos de aprendizagem de tutores - deveriam sim, estes profissionais ser reconhecidos também como docentes.

Para os entrevistados, a proposta de democratização da UAB/ EaD precisa, para sua efetividade, um maior cuidado em relação aos polos e à plataforma Moodle. É comum problemas técnicos na plataforma, ou condições precárias nos polos (falta de biblioteca, falta de acesso à internet). Dada as desigualdades regionais presentes no país, a política institucional e pública deveria fornecer bases, sobretudo para municípios mais pobres, para que haja condições iguais de acesso e formação com qualidade dos alunos, a partir da realidade destes. Atualmente, segundo a visão de dois entrevistados, a política de $\mathrm{EaD}$ não tem primado por esse viés:

[...] quando você garante a democratização da educação? É quando você não da só acesso, é quando você dá formação efetiva. Quando é que eu garanto o direito de educação? Quando as pessoas aprendem. Então, se quero EaD que vai ter lá na ponta, que deveria ter uma condição, livro, biblioteca, acesso, e não oferece, então eu tô oferecendo acesso a EaD, não tô oferecendo permanência e sucesso. Isso democratiza? [...] Quando vou olhar os dados da EaD, a gente não tá garantindo a democratização, nem pro acesso, muito menos pra qualidade, ela vai se efetivar no dia em que ela oferecer acesso com educação de qualidade. (ENTREVISTADO 2)

Eu acho que hoje a luta nossa não é mais interna, nossa, da UnB, ela ganhou uma outra dimensão, e uma dimensão muito difícil da gente combater que é a forma como a CAPES vê a EaD, a forma como ela financia, como é que ela pensa $\mathrm{EaD}$. [...] temos resistências internas à EAD [hoje], mas muito por causa do modelo de política que a CAPES tá implantando. (ENTREVISTADO 3)

\section{APONTAMENTOS FINAIS}

Nas entrevistas com os docentes (professores supervisores) da FE/UnB-UAB, detectaram-se diversos exemplos da existência de estratégias de ação pedagógica diferenciada frente às diferenças e desigualdades de capital cultural dos alunos que esbarram para sua efetivação e desenvolvimento, em limitações institucionais / administrativas e objetivas/estruturais de gravidade significativa. Os principais fatores que provocam a permanência de lógicas de indiferenciação e a consequente reprodução no sistema de ensino dentro dessa nova modalidade são de caráter objetivo, da condição de 
trabalho docente e institucional. Como afirmou categoricamente um entrevistado: as condições objetivas dessa educação estão cada vez, mais restritas.

A existência de um habitus sensível (ou "consciente", como quer Perrenoud) às diferenças e à utilização das NTICs, renovado constantemente na prática e na comunicação com os tutores, assim como as críticas e relatos de desgastes e desilusões registradas nas entrevistas, reforçam a ideia da primazia dos fatores objetivos como obstáculos à ação pedagógica diferenciada e dão uma visão de homogeneidade de habitus no recorte analisado. Por isso mesmo, a proposta de Perrenoud de uma formação mais consciente de um habitus não pode ser, nesse caso, a solução completa para a indiferenciação.

Nas entrevistas, os problemas e desafios da UAB mais apontados pela experiência de docência, direta ou indiretamente, foram:

- Limitações ou condições ruins de estrutura dos polos, em aspectos como internet, fotocópia, acervo de livros e periódicos, espaços para convivência, transporte, assim como das salas virtuais (plataforma Moodle);

- Baixo nível de institucionalização da EaD na UnB, via indução da UAB, impactando em frágeis vínculos trabalhistas no sistema bolsista de tutoria e sobrecarga do docente, tanto com os supervisores quanto com os tutores, além do pouco número de bolsas disponibilizadas (equipe pequena de trabalho).

Acredita-se que esses dois eixos se somam a outras características que contribuem para a evasão do curso, analisada por Lopes, Lisniowski e Jesus (2012), e dificultam as pretensões democratizantes da EaD, possibilitando assim a continuidade da reprodução e do dualismo educacional (a UAB como uma "instituição de ensino" em paralelo à UnB que é a instituição universitária "de fato"). Segundo a pesquisa, dificuldades estruturais impactam negativamente no acesso ao conteúdo, na comunicação e contato com os agentes educativos. Vale ressaltar que esses problemas apontados não anulam os esforços voluntários de docentes, tutores e gestores e suas consequentes melhorias e inovações. Porém, seria pouco realista esperar desse voluntarismo modificações amplas que a UAB necessita, em âmbito nacional e local. Essas modificações se referem a instâncias das políticas públicas e institucionais mais amplas. Como disse um docente: Nós [profissionais envolvidos diretamente com o trabalho pedagógico na $U A B]$ não podemos fazer milagres (ENTREVISTADO 3). 
Essas limitações, que proveem de âmbitos para além da ação pedagógica restrita, que emana do habitus professoral, repercutem negativamente na possibilidade de maior interação pedagógica e social entre docente-tutor-aluno-comunidade, mediadas pela instituição, organicamente consolidada, que possibilite o (re)conhecimento da cultura local e a criação de uma comunidade educacional.

A fim de compreender a importância dessa maior interação, pode-se transferir o foco do conceito de habitus, utilizado aqui para analisar os professores supervisores, para a formação docente na EaD. Um habitus profissional, como visto, necessita e se articula de vivências extra-curriculares, mobilizando e ampliando capital social, muitas vezes possíveis apenas além dos espaços virtuais. Nesse aspecto, Lopes, Lisniowski e Jesus (2012) também apontam que a causa mais relevante para a evasão foi a "ausência de interação presencial com colegas, professores e tutores".

As comunidades educacionais na EaD exigem uma articulação entre o real e o virtual. Diferente das comunidades reais, as comunidades virtuais não se encerram em limitações geográficas ou mesmo temporais, e têm num aparelho com acesso à internet, via celular ou computador, sua condição técnica primeira. Fala-se primeira, pois a constituição de uma comunidade virtual, incluindo a pedagógica, também envolve fatores sociais que ultrapassam aspectos técnicos de uma transferência informacional. Essa articulação entre real e virtual passaria também por utilização de outras tecnologias de modo integrado, já que, em duas entrevistas, houve a crítica de como a plataforma virtual tem determinado as relações docentes e limita regional e culturalmente a democratização da educação. Nesse novo modelo de maior relação entre os envolvidos com o sistema, os polos teriam um papel mais presente e, consequentemente, seria possível a criação coletiva de uma cultura e identidade acadêmica com práticas próprias de acordo com a realidade local, que não se limitem somente ao âmbito individual e da virtualidade, mas sim da coletividade e regionalidade (lugar). Com isso se ultrapassariam as barreiras do ensino, entendido como limitada instrução individual, "transmissão de conhecimento" (ENTREVISTADO 3), viabilizando assim uma estrutura para a diferenciação pedagógica que leve em conta as diferenças e as culturais locais e combatendo, de maneira não excludente, as desigualdades de capital cultural exigidos pelo sistema de ensino e seu arbitrário cultural, além de questioná-lo em si. Concorda-se com Wolton (2007, p. 136-7) quando diz "não se pode por si mesmo acessar diretamente o conhecimento. É preciso 
tempo, muito tempo, e as novas tecnologias fazem sonhar que é possível economizá-lo [...] possibilitar o acesso à informação é um progresso, mas não é o suficiente para criar uma certa igualdade."

Porém, ao lado de características diferenciadoras e progressistas do habitus professoral na EaD, também se pode deduzir neste, com mais clareza, certa ambiguidade implícita: a consciência das limitações do sistema, e de suas perpetuações desiguais, não bloqueia, por completo, sua aderência ao sistema UAB. Aceitar a docência, mas não aceitar a possibilidade de se tornar um discente da EaD um dia, como foi o caso de um docente entrevistado, é uma mostra de certa desconsideração subjetiva à $\mathrm{EaD}$, como alternativa eficiente para a sua aprendizagem, por exemplo. Ou, no mínimo, a crença de que a discência a distância requer características diferenciadas da discência presencial. Desilusões e conformismos, mesmo que inconscientes, denunciam uma espécie de silenciamento e consentimento subjetivo e/ou político, que limita posturas de antagonismo do sujeito. Ou uma disputa mais desiludida, contemplativa e/ou realista. Da mesma forma, o habitus dos professores supervisores entrevistados busca uma legitimação/distinção de sua posição, estabelecendo, na "luta democrática" pela diferenciação pedagógica, relações involuntárias de violência simbólica, como expressa sutilmente na relação desses professores com os tutores.

Um fenômeno descrito por Bourdieu (2010, p. 223) parece se encaixar aqui: o de "dupla consciência", onde o sujeito sabe o que está oculto sob sua ação, mas continua legitimando-a e "jogando o jogo”, de forma mais ou menos cínica ou desacreditada.

Conclui-se assim que faltam à EaD da UnB-UAB a construção, que leva em conta aspectos ausentes atualmente nos níveis objetivos do sistema, de uma flexibilidade híbrida própria que não negligencie o âmbito social da educação, e as interações que isso inclui, tanto em ambiente virtual, mas, sobretudo, no presencial, que não deve ser entendido como desperdício de tempo, ou inflexibilização, mas tempo necessário de formação e construção do saber que é social. Assim como não negligenciar os atendimentos pedagógicos individualizados e específicos, que já ocorrem, frutos de muito esforço docente. Para isso, o fortalecimento dos papéis dos polos - como centros de formação -, assim como uma maior institucionalização da EaD na instituição de educação superior, impactará nas relações e condições de trabalho docente mais seguras - apropriar-se da tecnologia, ampliar e potencializar as relações reais, não as substituindo. Essas 
são apenas algumas modificações fundamentais e emergenciais para que a EAD, do âmbito do sistema UAB, se transforme e alcance o nível de alternativa de educação superior democrática, podendo efetivar até mesmo as pretensões progressistas já presentes no habitus professoral na EaD, hoje ambíguas.

Com essa pesquisa, espera-se ter apresentado contribuições que transbordem a instituição analisada e apontem para um novo modelo nacional de EaD. Diferentemente do que diz a ideologia tecnológica, a técnica não é a solução messiânica para os problemas educacionais contemporâneos, mas um dos instrumentos possíveis, que está envolta em projetos sociais. "Tecnificar" problemas sociopolíticos, como a reprodução de uma dualidade na educação, é mistificar suas causas e suas soluções.

\section{REFERÊNCIAS}

AYED, C. B. As desigualdades socioespaciais de acesso aos saberes: uma perspectiva de renovação da sociologia das desigualdades escolares? Educ. Soc., Campinas, v.33, n.120, p. 783-803, set. 2012.

BOURDIEU, P. Compreender. In: (Org.). A miséria do mundo. 6.ed. Petrópolis: Vozes, 2007. p. 693-732.

. Escritos de educação: Pierre Bourdieu. NOGUEIRA, Maria A.; CATANI, Afrânio (Orgs.). 11. ed. Rio de Janeiro: Vozes, 2010.

Pierre Bourdieu entrevistado por Maria Andréia Loyola. Rio de Janeiro: EdDUERJ, 2002.

Razõos práticas: sobre a teoria da ação. 9. ed. Campinas: Papirus, 2008.

.; PASSERON, Jean-Claude. A reproducão: elementos para uma teoria do sistema de ensino. 2. ed. Rio de Janeiro: Vozes, 2009.

BRASIL. Decreto $n^{\circ}$ 5.622, de 19 de dezembro de 2005. Regulamenta o art. 80 da Lei no 9.394, de 20 de dezembro de 1996, que estabelece as diretrizes e bases da educação nacional.

BURAWOY, Michael. O marxismo encontra Bourdieu. Campinas, SP: Editora da Unicamp, 2010. CAPES. O que é a UAB. Disponível em: <http:// uab.capes.gov.br/index.php?option=com_ content\&view $=$ category\&id $=6 \& I$ temiD $=13>$. Acesso em: 21 jul. 2013.

COORDENAÇÃO Operacional de Ensino de Graduação a Distância. Universidade de Brasília. UAB-UnB. Disponível em: <http://www.uab.unb.br/>. Acesso em: 15 jul 2012.

CASASSUS, Juan. A escola e a desigualdade. Brasília: UNESCO, 2007.

DUBET, François. As desigualdades multiplicadas. Rev. Bras. Educ., São Paulo, n. 17, p. 5-19, maio/ago. 2001.

BOLTANSKI, Luc. Usos fracos e intensos do habitus. In: ENCREVÉ, Pierre; LAGRAVRE, Rose-Marie (Coord.). Trabalhar com Bourdieu. Rio de Janeiro: Bertrand Brasil, 2005, p.155-163. 
FRIGOTTO, G. Os circuitos da história e o balanço da educação no Brasil na primeira década do século XXI. Rev. Bras. Educ., Rio de Janeiro, v.16, n.46, p. 235-254, abr. 2011.

LOPES, Ruth Gonçalves de; LISNIOWSKI, Simone Aparecida; JESUS, Girlene Ribeiro. Políticas públicas de educação superior a distância: um estudo preliminar das causas de evasão em curso de pedagogia a distância oferecido no âmbito do sistema Universidade Aberta do Brasil. In: REUNIÃO ANUAL DA ANPED, 35., 2012, Porto de Galinhas (PE), Anais eletrônicos...Porto de Galinhas (PE), 2012. Disponível em:<http://www.anped11.uerj. br/35/GT11-2385_int.pdf>. Acesso em 15 jul. 2013.

MEC/INEP. Censo da educação superior 2011: resumo técnico. Brasília: INEP, 2013.

PERRENOUD, Philippe. A pedagogia na escola das diferenças: fragmentos de uma sociologia do fracasso. Porto Alegre: Artmed, 2001a.

. O trabalho sobre o habitus na formação de professores: análise das prát

icas e tomada de consciência. In: et al. Formando professores profissionais: quais estratégias? Quais competências. 2. ed. Porto Alegre: Artmed, 2001b. p. 161-184.

SETTON, Maria da Graça J. A teoria do habitus em Pierre Bourdieu: uma leitura contemporânea. Rev. Bras. Educ., São Paulo, n. 20. p. 60-70, maio/ago. 2002.

SILVA, Marilda. O habitus professoral: o objeto dos estudos sobre o ato de ensinar na sala de aula. Revista Brasileira de Educação, São Paulo, n. 29, p. 152-163, maio./jun/ jul/ago. 2005. Disponível em: <http://www.scielo.br/pdf/rbedu/n29/n29a12.pdf>. Acesso em: 15 jul. 2012.

SOUSA, Carlos Alberto Lopes de. 'Professor, quero ser oprimida!': situação-limite e atos-limites no habitus professoral. Linhas Críticas, Brasília, DF, v. 18, n. 37, p. 551-568, set./dez. 2012.

WACQUANT, L. Esclarecer o Habitus. Educação \& Linguagem, São Paulo, v. 10, n. 16, jul./dez. 2007.

WOLTON, Dominique. Internet, e depois? / uma teoria crítica das novas mídias. 2. ed. Porto Alegre: Sulina, 2007.

\section{NOTAS}

${ }^{1}$ Capital cultural é um conceito central na teoria e crítica social e cultural de Bourdieu (2010), assim como o de capital social e outros correlativos, como capital linguístico ou simbólico. Capital foi um termo desenvolvido no âmbito da economia, redefinido pela teoria marxista. Refere-se a um valor que busca constantemente autovalorizar-se. Bourdieu amplia tal conceito para todo o espaço social, buscando envolver variáveis não-econômicas na configuração da reprodução das distinções sociais (BURAWOY, 2010). Assim capital cultural refere-se a um conjunto de aparatos, saberes e atitudes, aprendidos ou objetivados, que uma classe ou indivíduo detém ou no qual investe, numa relação de dominação, na busca da valorização, legitimação ou ascensão de sua posição. Capital social já se refere a uma rede de relações e contatos pessoais e sociais mobilizáveis e busca o mesmo objetivo. Os dois conceitos serão utilizados ao longo do artigo.

${ }^{2}$ Esse trabalho foi gerado no âmbito do projeto de pesquisa "Agentes Educativos, Capital Cultural e Mídias", reunindo estudantes de graduação e do Programa de Pós-Graduação em Educação da UnB e contou com o apoio do CNPq. A versão original deste trabalho 
gerou relatório de pesquisa sob o título "Habitus Professoral e Ação Pedagógica frente às Diferenças em Sala de Aula Virtual” (não publicado), sendo revisto e ampliado para fins de publicação no formato de artigo.

${ }^{3}$ Esta afirmação de Bourdieu foi feita em entrevista concedida a Maria Andréa Loyola (cf. referência no final do artigo).

${ }^{4}$ Informação disponível em: <http://www.uab.capes.gov.br/>. Acesso em: 21 jul. 2013.

${ }^{\mathbf{5}}$ No início do governo Dilma, a Secretaria de Educação a Distância foi extinta. A partir de então, a CAPES substituiu algumas das suas funções dentro do sistema UAB.

${ }^{6}$ Segundo a página eletrônica do Moodle (<https://moodle.org/>), este é um Software Livre para Gestão de Curso, conhecido como um Ambiente Virtual de Aprendizagem (AVA). O Brasil é o terceiro país mais presente nessa plataforma virtual.

${ }^{7}$ Vale ressaltar que na UnB-UAB, as atribuições são divididas da seguinte forma: professor autor, professor supervisor e professor revisor. O professor autor planeja e elabora a disciplina. O professor supervisor acompanha e orienta o trabalho do tutor quando da oferta da disciplina aos alunos e também participa de alguns momentos de interação junto aos estudantes. Em geral, predomina, no curso em análise, o trabalho de supervisão que é feito por quem elaborou a disciplina. O professor revisor faz a revisão da disciplina para uma nova oferta. Este também pode ser o professor supervisor.

${ }^{8}$ Uma disciplina com duração de quatro meses pode ser estruturada em temáticas ou questões a ser discutidas em fóruns de discussão e atividades elaboradas pelos estudantes em mais de uma semana (pesquisas de campo, roteiros de questões para aprofundamento, entre outras atividades). Já o planejamento semanal demanda que as atividades sejam realizadas pelos estudantes semanalmente.

${ }^{9}$ A resistência realista em termos políticos não se traduz num confronto aberto entre os agentes que atuam no próprio campo, firmando concepções de educação, de sociedade, visão de homem e mulher, negando a $\mathrm{EaD}$ ou um sistema público de ensino superior a distância. A resistência realista trata de atuar por dentro da instituição e sistema de ensino, “jogando o jogo nas regras existentes”, na crença de mudanças graduais ou em etapas.

Recebido: 29/08/2013

Aprovado: 10/03/2014

Contato:

Universidade de Brasília (UnB) / Faculdade de Educação

Departamento de Teoria e Fundamentos

Campus Darcy Ribeiro - Asa Norte

Brasilia | DF | Brasil

CEP 70.910-900 